\title{
Dor crônica e subjetividade em oncologia
}

\author{
Chronic pain and subjectivity in oncology
}

\author{
Ana Valéria Paranhos Miceli
}

\begin{abstract}
Resumo
A despeito dos avanços ocorridos nos dois últimos séculos ainda restam muitas dúvidas quanto à etiologia e à manutenção da dor crônica, e uma volta à história ajuda a compreender de que maneira vieram evoluindo suas definições, teorias e técnicas de tratamento, inclusive as psicológicas. H oje tem-se um consenso quanto ao caráter subjetivo e multifatorial da dor, 0 que requer uma abordagem detratamento especializada emultidisciplinar, demodo aidentificar e resolver os problemas de comunicação e mensuração da dor e a ampliar os cuidados terapêuticos oferecidos ao paciente e suporte prestado à família e cuidadores, e à equipe de saúde.
\end{abstract}

Palavras-chave: dor; dor crônica; psicologia; neoplasias; pacientes; cuidados paliativos.

\begin{abstract}
In spite of the advances ocurred in the last two centuries there are still many questions about ethiology and maintenance of chronic pain, and analysis of the history helps us understand the definitions, theories and techniques of treatment, including the ones related to psychological aspect, and how they were developed. At this moment, there is a consensus on the subjective and multifactorial nature of pain. It is necessary a specialized and multidisciplinar treatment approach to identify and solve the problems of communication and measurement of pain, and to amplify the therapeutical care offered to the patients, and the support provided to ther families/caregivers and to the health care team.
\end{abstract}

Key words. pain; chronic pain; psychology; neoplasms, patients; palliative care

Psicóloga. Clínica do Instituto N acional de Câncer, Setor de Psicologia do H ospital do Câncer I, Praça da Cruz Vermelha 23; 20230-130 Rio de Janeiro, RJ - Brasil. E-mail: ana.val@terra.com.br

Recebido em novembro de 2001. 


\section{INTRODUÇÃO}

A dor crônica acomete de $25 \%$ a $30 \%$ da população dos países industrializados, devendo ser considerada um sério problema de saúde. ${ }^{1}$ N o Brasil, a dor é a razão pela qual $75 \%$ a $80 \%$ da população procura o sistema de saúde, e a dor crônica, que acomete $30 \%$ a $40 \%$ da população brasileira, é a principal causa de faltas ao trabalho, baixa produtividade, licenças médicas, aposentadorias por doença e indenizações trabal histas. ${ }^{2}$

D oença alguma justifica que aceitemos que um indivíduo conviva com dor que pode ser debelada, controlada ou em muito aliviada. Em movimento internacional, várias instituições de saúde têm investido na formação de equipes multidisciplinares especializadas não somente em dor, mas sobretudo no tratamento dos pacientes com dor, reconhecendo a multiplicidade de fatores bio-psico-sociais na etiologia e na manutenção da dor crônica e a necessidade de tratar criteriosa e globalmente 0 paciente o quanto antes. A O rganização M undial da Saúde (OM S) preconizou o efetivo controle da dor como uma das três prioridades no sistema de saúde pública, sugerindo que cada governo inclua-o no seu sistema de saúde, assim como os cuidados paliativos, de modo a aliviar a dor e outros sintomas e a melhorar a qualidade de vida dos pacientes com câncer, sendo a educação e o treinamento dos profissionais de saúde, nas diferentes fases e tipos de cuidados, um elemento-chave para obtenção do tratamento adequado. ${ }^{3}$

\section{O FENÔMENO DOR}

Provavelmente por seu caráter subjetivo, quetanto dificulta um enquadramento preciso, a dor foi historicamente compreendida e explicada de forma mítica, mística ou religiosa. Dor e sofrimento eram inseparáveis, socialmente tidos como castigos merecidos pela provocação da cólera dos deuses ou ira divina, e ainda martírios necessários para a purificação e a salvação da alma. Tais conceitos parecem ter de algum modo se fixado no imaginário coletivo, posto que até hoje existem pacientes procurando saber 0 que fizeram de errado para merecer sua doença, sua dor, enquanto há outros acreditando que para crescer e amadurecer é preciso sofrer.

$\mathrm{N}$ a tradição européia, a dor foi um importante meio de coerção política, social e religiosa, sendo utilizada legalmente para ameaçar e punir os indivíduos e a coletividade. ${ }^{4}$ O suplício judiciário era uma das formas de manifestação do poder, mas o direito de punir e castigar era também uma maneira de buscar vingança pessoal e pública. $D$ as prisões nas masmorras, com sua função de trancar, privar de luz e esconder, ao dispositivo panóptico de vigilância e controle contínuos, ${ }^{5}$ o poder, com suas regras, já impunha castigos e sofrimentos também psicológicos.

Com 0 isolamento da morfina, no início do século $X I X$, os opióides são então desenvolvidos e em 1850, com a identificação dos receptores neurológicos e da transmissão dos impulsos nervosos, a dor física finalmente é separada do sofrimento social, tornando-se um fenômeno biológico, explicado fisiologicamente. Com a introdução da anestesia cirúrgica, em 1846, da anestesia local, em 1884 e da aspirina, em 1899, ${ }^{4} 0$ homem entra no século XX livre para não sentir dor.

Entretanto, apesar destes muitos avanços, somente as implicações neurológicas eram consideradas, o que explicava apenas em parte o fenômeno da dor. As dores que não tinham um substrato físico-orgânico claramente identificável continuaram inexplicadas até Freud provocar um corte epistemológico na história da Ciência, ao refutar a visão de mundo reducionista, mecanicista e determinista da física newtoniana e do pensamento cartesiano, dominantes desde 0 século XVII, com suas revolucionárias idéias reunidas no nascimento do século $X X$, sob 0 nome de Psicanálise.

No início do século XX, a Teoria da Relatividade de Einstein revoluciona a crença nas leis objetivas do U niverso, na existência da Verdade e na certeza da observação, e a Psicologia da G estalt conceitua que "o todo é mais do que a simples soma das partes" e alicerça a importância do contexto, uma vez que para haver percepção (então distinta de sensação) necessariamente precisaria haver uma diferença (figura/fundo). A partir de Einstein e das novas teorias psicológicas, a Ciência ruma para um novo paradigma, que é sistêmico, e onde o contexto é valorizado. 
N os dias atuais, é incabível pensar em corpo e mente que não seja como um sistema integrado. A distinção entre doença do cérebro e da mente, problemas neurológicos, psicológicos ou psiquiátricos refletem uma herança cultural infeliz e equivocada. ${ }^{6}$ D o mesmo modo, é inimaginável pretender tratar a dor ou qualquer doença que seja, mas sim tratar pessoas, e pessoas são muito mais do que os sintomas que apresentam. $E$ até mesmo a ação de tratar tem seu caráter de relatividade. Para o biólogo M aturana, ${ }^{7}$ o ser humano é um sistema com estrutura determinada e ao entrar em contato com 0 ambiente, o queacontecerá dependerá decada um, de sua estrutura no momento, e não diretamente do ambiente (este será um gatilho em menor ou maior grau, para as mudanças), sendo a interação instrutiva mera ilusão.

Como o indivíduo é singular, não se pode pretender que responda da mesma forma às intervenções externas, nem tão pouco que mantenha uniformemente suas respostas a longo prazo. Tratar um paciente requer não somente as considerações biológicas e psicológicas como também as familiares, sociais, econômicas e aquelas que estão nas relações estabelecidas entre os sistemas envolvidos: 0 indivíduo e seu universo e o sistema de saúde e de tratamento, com todas as suas múltiplas variáveis. $N$ ão basta tratar a dor, mas também o paciente e, além dele, os sistemas que com ele interagem.

\section{AS TEORIAS PSICOLÓGICAS}

Algumas teorias psicológicas trouxeram suas contribuições em direção à uma reinterpretação dos mecanismos da dor. À semelhança do conceito de homeostase, em 1895, Freud ${ }^{8}$ Iançou a idéia da existência de um princípio de constância do aparelho psíquico, formulando-a em 1920, como sendo uma tendência inerente ao sistema nervoso, para reduzir totalmente (Princípio deN irvana) ou pelo menos manter constante as excitações presentes, de modo a manter o equilíbrio do aparelho psíquico. ${ }^{9}$ Em 1926, Freud $^{10}$ considera todo processo mental de forma dinâmica, topográfica e econômica, havendo duas classes de instintos (de Eros e de $M$ orte) e três instâncias psíquicas: 0 ego representante da realidade; o id reservatório dos instintos de conteúdos inconscientes e o superego, juiz, censor do ego.
$\mathrm{N}$ a tentativa de explicar não somente a etiologia como também a manutenção de sintomas observados nas neuroses, Freud ${ }^{10}$ teoriza que um determinado impulso instintual geraria um desprazer, levando o ego a tentar suprimir tal impulso. Caso o ego fal hasse, em maior ou menor escala, este impulso ainda tentaria ser admitido no sistema consciente, e para tal encontraria um substituto, "mais reduzido, inibido e deslocado", isto é, o sintoma, que seria um compromisso entre o impulso inconsciente e as exigências defensivas, reduzindo assim a situação de conflito. 0 sintoma seria uma fuga para a doença, um benefício (ganho) primário, tendo a qualidade de uma compulsão. 0 esforço do ego para incorporar o sintoma acaba por aumentar a sua fixação, tornando mais difícil desfazer esse compromisso entre eles e levando o indivíduo, então, a tirar o melhor proveito da sua doença (ganho secundário).

A partir de Freud, considera-se a multiplicidade causal dos sintomas. $E$ sendo a dor um sintoma, um estado afetivo, a psicodinâmica da dor envolveria a predisposição à dor e os mecanismos de manutenção e perpetuação desta dor, lembrando que os estados afetivos têm a característica da subjetividade. Em 1926 Freud $^{10}$ observou que mesmo as dores físicas mais intensas deixavam de surgir quando havia um desvio psíquico ocasionado por outro foco de interesse e que a ansiedade realística (devida a perigos externos) podia mesclar-se à ansiedade neurótica (devida a perigos internos), manifestando-se de forma mais comedida ou desmedida.

Paralelamente à Psicanálise, a primeira metade do século XX nos traz informações novas, como o conceito de stress e a evidência da interação entre os sistemas nervoso e imunológico, ficando claro que as experiências cotidianas da vida poderiam causar impressões físicas no corpo e que toda doença afetaria a psique e o soma, como explicam as novas disciplinas: a Psiconeuroimunologia e a M edicina Psicossomática. ${ }^{11}$ A partir de então, a dor passa a ser vista como um fenômeno não somente biológico como também psicológico.

$\mathrm{N}$ a segunda metade do século $\mathrm{XX}$ as teorias cognitivo-comportamentais, em oposição à Psicanálise, afirmam que 0 
comportamento poderia ser modelado, alterado, enfraquecido ou fortalecido como resultado direto do ambiente, sendo a dor sensorial, "respondente", distinta da dor "operante", esta motivada por necessidades psicológicas. ${ }^{12}$ Ao contrário dos psicanalistas, os behavioristas acreditavam na simples causalidade existente entre a manutenção da dor e as influências ambientais e que a dor seria reforçadamente mantida apenas pelo ganho secundário através dela obtido, sendo desconsiderada a psicodinâmica da dor.

Também por volta dos anos 50 , os primeiros terapeutas de família e teóricos sistêmicos estudam a comunicação humana concluindo que, em condições de interação, é impossível não comunicar, e que toda comunicação tem um aspecto de conteúdo e um aspecto de relação, sendo portanto digital-manifesta, mas também analógica-latente. ${ }^{13}$ Pode-se afirmar que há mais de uma forma de se comunicar a dor. Pode-se ainda dizer que a dor, como qualquer outro sintoma, comunicaria aspectos que escapariam ao observador desatento e até mesmo àquele mais curioso, aspectos que não estariam claramente conscientes nem mesmo para 0 sofredor. Assim, diante de um paciente com dor é preciso pesquisar do que fala esta dor, e o que é que ela cala.

O s teóricos sistêmicos, primeiramente, viam o sintoma como uma disfuncional característica do sujeito, mas a afirmativa, em 1977, do físico Prigogine de que um sistema tenderia tanto à homeostase quanto à mudança, havendo "ordem através da flutuação" levou à consideração do sintoma como uma característica do sistema. ${ }^{14} \mathrm{D}$ etodo modo, o "sistema observador" continuou sendo visto como distinto do "sistema observado" até a década de 80 , quando 0 M ovimento Construtivista defendeu a idéia da não existência de dois sistemas separados, mas de apenas um, chamado por Von Foerster "sistema observante", onde a realidade é coconstruída sendo o conhecimento, portanto, uma ilusão, uma invenção.

Ao trazer estes conceitos para a prática clínica, percebe-se que são importantes não somente os contextos que contribuíram para a produção e manutenção da dor, sendo 0 sistema familiar um exemplo, como também o contexto que envolve o momento do diagnóstico e o tratamento oferecido.
Pensando assim, qualquer diagnóstico seria uma invenção, uma co-produção, pois envolveria não somente os sintomas - fala do paciente, como também os sinais - fala do técnico, este também possuidor de sistema próprio de crenças e valores e passível da ocorrência e da alternância dos mais variados estados afetivos. D e certa forma o paciente denuncia esta co-produção, especialmente quando, ainda assintomático, tem o câncer precocemente diagnosticado, dizendo-nos: "Ele (o médico) é quem diz que eu tenho isto (leia-se: fez isto a mim, deu-me isto)..., mas eu não sinto nada!"

Como vemos, o tratamento começa pelo cuidado na hora do diagnóstico.

\section{DEFINIÇÃO DE DOR}

0 fenômeno dor sempre intrigou e desafiou a comunidade científica. A International Association for the Study of Pain (IASP) foi fundada, em 1973, visando a reunir profissionais interessados em aprofundar estudos sobre a dor e a trocar experiências clínicas, levando a uma maior sistematização do tratamento da dor, oficialmente definida como sendo uma "desagradável experiência sensorial e emocional associada a um dano atual ou potencial do tecido, ou descrita em termos deste dano". 15

0 termo "desagradável" desta definição já denota 0 caráter subjetivo da dor, que abrangeria mecanismos fisiológicos, psicológicos e comportamentais, sendo que o seu experenciar sucessivo criaria um "comportamento de dor" que envolveria os pensamentos, os valores culturais, e o ganho secundário. ${ }^{1}$

Os fatores neuro-hormono-químicos também fazem parte, junto com os biológicos, psicológicos e comportamentais, da complexa síntese que define a dor. ${ }^{16} \mathrm{~A}$ relação entre estímulo psicossocial e a resposta endócrina foi explorada nos anos 70-80, e a Psiconeuroendocrinologia estabeleceu-se como disciplina. ${ }^{17} \mathrm{M}$ ais adequado seria dizer Psiconeuroimunoendocrinologia, por revelar a inter-relação entre estes sistemas, ligação esta que explicaria a associação encontrada, na prática clínica, entre estresse psicológico e infecção, e a associação encontrada entre depressão e uma menor resistência à infecção ea propensão ao desenvolvimento, morbidade e mortalidade por câncer. ${ }^{18}$ 


\section{OS MECANISMOS DA DOR}

Muitos são os desafios encontrados quando se procura compreender os mecanismos de dor, dentre eles a "dor fantasma", relativamentecomum em pacientes amputados. Deve-se estar ciente da possibilidade de ausência de dor na presença de um estímulo nocivo, da percepção de dor na ausência de um estímulo nocivo e da manutenção da dor mesmo após o desaparecimento deste, quando a resposta de dor na ausência do estímulo que a originou tornar-se-ia uma resposta a diversos estímulos semelhantes ou não ao original, encontrando uma maneira de se manifestar. Só não se sabe por que isto acontece, e por que com al gumas pessoas sim e com outras não.

Estudos sobre a capacidade dos paraplégicos sentirem seus corpos revelaram que o cérebro poderia gerar qualquer tipo de experiência provocada normalmente por um estímulo sensorial, e que a dor fantasma poderia aumentar devido a problemas psicológicos, excitação ou depressão dos pacientes, sendo possível, ainda, associar um estado de bem estar à diminuição da dor. ${ }^{19} \mathrm{~A}$ etiologia da dor fantasma é desconhecida, mas supõe-se haver uma memória somato-sensorial que não se localiza especificamente em uma região do cérebro, mas envolve, sim, uma complexa interação de redes neurais no cérebro. ${ }^{20}$

Já em 1933 Freud $^{21}$ acreditava que os estados afetivos, como a dor ou a ansiedade, seriam uma reprodução de um evento antigo (experiências traumáticas primevas) que representaria uma ameaça de perigo, uma vez que paralisaria a função reguladora do princípio de prazer. Para ele, a partir do momento em que uma experiência dolorosa primeva se gravasse no psiquismo, ao ocorrer uma situação semelhante, por mais parcial que fosse, os estados afetivos precipitados pela antiga experiência dolorosa seriam revividos como símbolos mnêmicos.

A resposta consensualmente confiável para esta e outras questões ainda está por vir, mas atualmente concorda-se que múltiplos fatores em diversas esferas contribuem, todos, para o desenvolvimento das síndromes de dor crônica, que as vias da dor são a sensação, a transmissão, a percepção e a reação, e que as medidas de sensibilidade são individuais, assim como todos os demais mecanismos de dor.

Esta subjetividade que permeia tais mecanismos leva-nos a rejeitar a existência de uma verdade quanto à etiologia, à manutenção e à eficácia do tratamento da dor. A filosofia kantiana do fim do século XVIII já havia distinguido o objeto em si (objeto "real"), que é inatingível, do objeto como ele aparece (objeto percebido e interpretado individualmente), este sim por cada um cognoscível. ${ }^{22} \mathrm{E}$ a Psicanálise, por outro lado, advertiu ser possível que um desejo ou uma ameaça sejam tão fortemente experimentados a ponto de serem reconhecidos, pelo indivíduo, como fatos reais.

C ada pessoa vai perceber, reagir e elaborar sua dor de forma particular e assim, o ser humano estará sempre desafiando os saberes e reformulando novas teorias e técnicas. Para $\mathrm{N}$ asio, ${ }^{23}$ a dor resulta de uma dupla percepção: uma que é externa, somato-sensorial, voltada para captar a sen sação dolorosa, e outra que é interna, somato-pulsional, voltada para captar o transtorno psíquico que se segue após a primeira.

$\mathrm{N}$ ão se pode dizer 0 que é realidade absoluta, já que as diversas imagens (perceptivas, evocadas a partir de um passado real e evocadas a partir de planos para o futuro) são construções do cérebro, sendo reais para quem as têm. As imagens mentais seriam construções momentâneas, tentativas de réplica de padrões que já foram experienciados, e o que seria armazenado não seria a imagem em si, mas um meio de reconstruir um esboço dessa imagem. ${ }^{6}$

Sendo a essência do objeto de observação, o objeto em si, inatingível, não existiria objeto natural, mas sim cultural, histórico, lembrando aqui que as ciências que visam a um saber sobre o homem originaram-se do desejo de exercer um saber-poder ligado à necessidade de vigilância e controle sóciopolítico, utilizando-se hoje do exame do mesmo modo como um dia a Inquisição utilizou-se da confissão. ${ }^{24}$

0 profissional deve, pois, ficar atento aos próprios conteúdos internos, ao seu "jeito de ser", aos seus preconceitos e expectativas, e ao estado de humor que apresenta no momento do atendimento ao paciente, posto que também ele influencia os caminhos da dor daqueles de quem cuida. 


\section{COMUNICAÇÃOE MENSURAÇÃO DA DOR}

A forma de comunicação da dor dependerá de fatores tais como idade do paciente, sexo, estrutura de personalidade, funções cognitivas, história pessoal, contexto sócio-familiar e de dor, estado afetivo e condições psico-orgânicas do momento. Acredita-se que a comunicação da dor dependerá ainda, diretamente, da qualidade do ouvinte, da disponibilidade real e sincera de escuta, da comunicação inequívoca, pelo ouvinte ao paciente, de sua determinação inarredável em dele cuidar.

Para medir a presença e a severidade da dor, é preciso considerar o auto-relato, as observações clássicas, e também outras variáveis como depressão, ansiedade, 0 significado da dor para o paciente, o seu suportefamiliar eseus possíveis receios quanto a incomodar ou levar o seu médico a desistir do tratamento, pela fantasia de progressão de doença, caso seja confessado um aumento de sua dor. ${ }^{25}$

Como nenhum parâmetro isolado pode ser fidedigno, atualmente procura-se fazer uma mensuração combinada da dor do doente, considerando-se o auto-relato; apercepção e comunicação da dor pelo paciente; crenças, fantasias e expectativas (do paciente, de seus familiares e da equipe de tratamento) relacionadas à esta dor; a história pessoal; o contexto sócio-familiar; as alterações afetivas, sociais, familiares e comportamentais; o relato da família; o comportamento e a história de dor; a postura corporal; a mímica facial; os sinais fisiológicos; os marcadores biológicos; as escalas específicas e qualquer outra forma de expressão encontrada.

A Escala Análogo-V isual de D or (EAV), ${ }^{26}$ que por suas limitações é muitas vezes pouco utilizada e/ ou compreendida, éum importante instrumento na mensuração da dor crônica, pois ajuda o paciente a compreender melhor quando e quais fatores influenciam a sua percepção da dor, levando-o, ainda, a um mai or comprometimento com as informações que fornece, uma vez que estas serão sempre parâmetros para a avaliação da adequação do tratamento. M uitas vezes há resistência do paciente a este método, sendo necessário que ele compreenda bem os objetivos e confie que a intenção do profissional é tratá-lo eficaz e continuamente, e que este não desistirá de manter seu tratamento, no caso designificante melhora, nem ficará decepcionado e aborrecido desistindo de tratá-lo, no caso de pouca ou nenhuma resposta.

Para tornar-se uma linguagem confiável, a EAV deveria ser utilizada de forma consensual pela equipe, preferencialmente com as respostas da dor referida no momento da consulta e com as respostas da "dor em média" relatadas pelo paciente, sinalizandose, em ambos os casos, as condições afetivas e de medicação. Vale ressaltar a necessidade de reorientação periódica a pacientes e familiares sobre vários aspectos que envolvem o tratamento farmacológico, desde os efeitos colaterais, receios e preconceitos, às demais e inúmeras fantasias e dificuldades que levam ao uso irregular da medicação, comprometendo o sucesso do tratamento.

Observa-se que alguns pacientes, sobretudo as crianças, os adolescentes e os idosos, muitas vezes podem levar a erros de julgamento ocasionados por problemas na comunicação, justificados pelos motivos mais variados e já classicamente reconhecidos e descritos, como a supervalorização, a desvalorização e a negação da dor. Gostaríamos aqui de incluir o problema da omissão da dor. " $X$ ", uma menina de sete anos, hospitalizada em estado bastante grave, aguardava a remota possibilidade clínica de ser elegível para iniciar tratamento quimioterápico. Seu comportamento era de total isolamento, cobrindo-se com o lençol de seu leito até à cabeça, em posição fetal, e reagindo agressivamente a qualquer tipo de aproximação feita, até pelos familiares. Recusava comida, banho, brinquedos, visita, e todo e qualquer procedimento médico e de enfermagem de rotina, chorando e gritando de tal forma que por vezes impedia a realização dos mesmos. Quando por nós abordada, " $X$ ". revelou que sentia "dor muito forte", e ao ser questionada quanto ao motivo pelo qual não havia comunicado a sua dor, ela respondeu, com raiva: "Eu já falei um montedevezeseninguém faz nada!" " $X$ " estava, sim, medicada, mas não a contento, e assim perdera a confiança em todos à sua volta, sentindo-se sozinha e desamparada, desistindo de solicitar ajuda. U ma vez psicologicamente 
acompanhada etendo sua dor controlada, " $X$ " começou a reagir, a sorrir, e, "curiosamente", a melhorar a ol hos vistos, adquirindo os sinais clínicos necessários para iniciar seu tratamento oncológico.

Em estudo realizado para determinar se haveria diferença, nos pacientes oncológicos externos, entre a percepção que o paciente tinha de sua dor e a percepção que seus familiares tinham acerca de sua dor quanto à intensidade, duração, estado de humor e qualidade de vida, concluiu-se que os pacientes oncológicos que têm percepção de dor diferente da do seu familiar tendem a ter, dentre outros sintomas, mais distúrbios de humor, mais fadiga e menos bem-estar psicológico e interpessoal. E seus familiares têm níveis de depressão e ten são aumentados, sendo que $30 \%$ sentiram incapacidade de lidar com a dor do paciente, enquanto $22 \%$ sentiram grande estresse devido ao sofrimento do paciente. ${ }^{27} \mathrm{O}$ bviamente lembramos aqui que percepções incongruentes por parte da equipe também resultam em problemas no tratamento.

$\mathrm{Na}$ avaliação do paciente com dor crônica, deve-se, ainda, ficar atento tanto à co-morbidade quanto ao diagnóstico diferencial entre dor e outras síndromes de características predominantemente orgânicas e psicológicas. Pesquisa com pacientes com dor crônica demostrou que o aumento da duração da dor favorecia a depressão, e que os pacientes deprimidos tinham aumento da percepção de dor, menos tolerância à dor e beneficiavam-se menos do tratamento. ${ }^{28}$

\section{DOR EM PACIENTES ONCOLÓGICOS}

A dor em câncer pode ser causada pela doença, a ela relacionada, resultante de procedimentos diagnósticos e de tratamento, ou ainda causada por um transtorno concorrente. A prevalência de dor crônica é de $30 \%$ a $50 \%$ nos pacientes em tratamento oncológico para tumoressólidos, subindo para $70 \%$ a $90 \%$ naqueles com doença avançada no momento do diagnóstico. ${ }^{29}$

No Brasil, as neoplasias são a terceira causa de morte, a segunda por doença, e 0 Instituto $\mathrm{N}$ acional de $\mathrm{Cancer}{ }^{30}$ estimou que para 0 ano de 2001 haveria 305.330 novos casos de câncer. Embora a incidência e a mortalidade por câncer continue a crescer, os países em desenvolvimento investem muito nos esforços curativos e pouco e inadequadamente nos cuidados paliativos, quando uma grande maioria já apresenta doença incurável à época do diagnóstico. ${ }^{31}$

O câncer por si só já implica na perda de energia, amigos, e saúde, e a dor não aliviada gera ansiedade e sintomas depressivos, agravando tais perdas e prejudicando as funções cognitivas, as atividades diárias e sociais e o sono, que é interrompido pela dor em $58 \%$ dos pacientes. ${ }^{32}$

As intervenções não-farmacológicas, como as técnicas psicológicas, a acupuntura, a fisioterapia, a RXT e a cirurgia, dentre outras, embora muito importantes no tratamento do paciente com dor oncológica, são raramente indicadas e dificilmente disponibilizadas pelos centros de tratamento oncológico. ${ }^{33}$

Segundo a OM S, ${ }^{34}$ é possível controlar a dor em cerca de $90 \%$ dos pacientes oncológicos, mas na maioria das unidades de saúde falta conhecimento, habilidade e até interesse no manejo da dor e muitas vezes os esforços daqueles que empenham-se no tratamento adequado esbarram nos preconceitos de seus colegas e da população em geral, e em questões de cunho político, econômico e social.

\section{A DIMENSÃO DA DOR}

Algumas dores crônicas são mais dificilmente controláveis em determinado paciente, fazendo-se necessário que ele tenha que conviver com ela, em algum nível, e com as limitações por ela trazidas. U ma maior aceitação de sua dor leva o paciente a conhecêla e controlá-la melhor, esforçandose para ter uma vida satisfatória apesar dela. Isto implica em relatos de dor de intensidade mais baixa, menos ansiedade e sintomas depressivos e menos incapacidade física e psicossocial. ${ }^{35}$

A experiência de dor crônica é estressante tanto para o paciente quanto para seus familiares, amigos, cuidadores e também para a equipe que 0 trata. Sabese que o sistema familiar funciona de acordo com padrões e regras próprios, e que quando um membro adoece toda a organização deste sistema é abalada, "adoecida", compelida a mudanças muitas vezes complicadas que podem ser 
difíceis de elaborar. A despeito da multiplicidade de modalidades de tratamento que um Centro Muldisciplinar de D or pode oferecer, é o familiar, o cuidador, quem se responsabiliza, em grande parte dos casos, pela administração da medicação e pelo oferecimento de outras medidas que aliviam a dor, pelo transporte do paciente, inclusive para a realização do tratamento, pelo seu bem estar físico e psicológico. Cabe à equipe orientar os familiares/cuidadores do paciente, e se preciso tratá-los psicologicamente, formando uma aliança de mútua confiança e divisão de responsabilidades e buscando identificar e solucionar problemas por eles enfrentados ou criados.

É preciso não apenas demandar, mas também viabilizar mudanças. A percepção e a reação do adulto, e principalmente da criança e do adolescente, à sua dor, dependerá não somente de si mesmo e de sua família, como já foi visto, mas também do ambiente hospitalar, da rotina hospitalar e da equipe terapêutica. Pequenas modificações e grandes mudanças devem ser consideradas, em micro e macroescalas, para realmente tratar um indivíduo que tem dor.

\section{TRATAMENTO DO DOENTE ONCOLÓGICO COM DOR}

Considerando que sentir dor não é natural, ainda que compreensível, e que ausência de dor é um direito do paciente, deve-se agrupar esforços no sentido de aliviar e controlar a sua dor, sabendo-a múltipla e dinâmica e adequando periodicamente 0 tratamento oferecido.

Os pacientes com dor teriam seis necessidades universais: conforto, evitação das reações adversas, preservação das atividades funcionais diárias, prevenção da recaída, qualidade de vida satisfatória e confiança renovada, sendo seis os princípios do manejo de dor: respeito ao paciente e à dor, saber quando tratar a dor, tratar cedo e agressivamente a dor, tratar as causas subjacentes à dor, tratar os aspectos psicológicos da dor, e a abordagem multidisciplinar. ${ }^{36}$

0 paciente oncológico pode apresentar também dor aguda, muitas vezes provocada por diagnóstico e ou procedimento terapêutico, sendo importante a analgesia inclusive preventiva tanto desta quanto da dor crônica, procurando identificar e minimizar efeitos colaterais do tratamento em todos os aspectos (fisiológico, funcional, cognitivo, social, psicológico). Em caso de dor crônica, todas as demais terapias não farmacológicas são necessárias no efforço conjunto de atender, dentro do possível, às expectativas do paciente promovendo maior alívio, conforto e funcionalidade.

Ao acolher e compreender a dor do paciente, o psicólogo da equipe 0 ajuda a identificar as influências da dor na sua vida e as influências internas e externas na manutenção da dor. Ao se trabalhar a identidade, a auto-imagem corporal, a autoestima e a autonomia do paciente, amplia-se o foco levando-o a ver além da sua dor e da sua doença, facilitando a elaboração de seus novos limites e possibilidades através de ressignificações e redirecionamentos, sinalizando os seus recursos adaptativos internos e estimulando o fortalecimento de suas relações interpessoais, sociais, familiares e profissionais ou escolares.

$\mathrm{N}$ ão se pode traçar aqui as várias dificuldades encontradas no empenho de um tratamento adequado, pois para isto deve-se abordar desde os preconceitos ainda existentes entre nós até a política governamental, mas é preciso atenção especial para a urgência de mudanças na avaliação da dor em crianças e idosos, que, por dificuldades de comunicação inerentes à idade ou a problemas subjacentes, têm sua dor muitas vezes confundida com "manha", "cansaço", "incômodo" ou "tristeza", deixando assim de receber tratamento e controle de sintomas devidos. O s adolescentes vivem, por sua vez, questões concernentes a esta peculiar fase do desenvolvimento humano, oscilando entre a súbita maturidade, a infantil dependência e a "rebeldia" na tentativa de diferenciação da independência, podendo utilizar-se, perigosamente, de aspectos relativos à sua doença ou à sua dor como parte deste natural exercício de busca de identidade própria.

Somente em dezembro de 1998 houve um consenso $^{37}$ quanto ao manuseio da dor em crianças, preconizando também para elas 0 sério e adequado tratamento farmacológico e não farmacológico. Para tanto, é fundamental observar os familiares e cuidadores no trato com os doentes e ouvir suas considerações, mas o profissional deve ainda identificar suas 
próprias dificuldades e tentar superá-las. Perceber ou ter que aceitar que alguém, sobretudo uma criança, um jovem, ou um idoso sofre de profunda dor e espera por cuidados que são sabidamente limitados é difícil também para o profissional que, quando impotente, não consegue evitar seu próprio sofrimento. Por isto pode-se dizer que a dor do paciente oncológico não é somente dele, mas é sistêmica: é também de seu universo familiar, social, e de todos que dele cuidam e tratam. É o que podemos chamar de dor geral.

\section{CUIDADOS PALIATIVOS}

Além dos cuidados que visam ao alívio da dor e à promoção da ampla reabilitação do paciente oncológico, em todas efferas de sua vida, é preciso atenção aos cuidados paliativos, que devem começar desde 0 diagnóstico de doença avançada até a fase final de vida. 0 conceito de dor total foi cunhado em 1964 por Cicely Saunders ${ }^{38}$ para mostrar quea dor em câncer era física, emocional, social e espiritual, sendo posteriormente acrescentadas a dor interpessoal, a familiar e a financeira.

D eve-se distinguir tratamento paliativo de cuidado paliativo. 0 paciente com dor e doença avançada, mas que ainda é elegível cirurgicamente ou para tratamento adjuvante, difere daquele ao qual só é possível oferecer algum tipo de conforto, mas nenhuma esperança de controle da doença. Parece-nos que o "paciente tratável" investe mais em sua "melhora", mas também recebe maior investimento, tanto da equipe quanto dos familiares. Parece que o profissional "esquece" ou "não acredita" no caráter paliativo do tratamento, o que só ficará claro quando o paciente receber o "carimbo" de "fora de possibilidades terapêuticas atuais", - carimbo da desistência médica ou institucional em tentar reverter ou conter 0 avanço da doença, quando então cessarão os tratamentos, exceto os cuidados clínicos, os de enfermagem e aqueles oriundos de outras categorias profissionais. Este é um momento especialmente delicado para todos.

Congruentemente com este "paciente cuidável", geralmente desmotivado, que está em fase final de doença, a resistência da equipe e dos familiares parece ir diminuindo. Provavelmente seja este um mecanismo natural de defesa, pois começa-se a elaborar a idéia da separação, pela morte, antes mesmo dela chegar. E isto ocorre de várias maneiras, desde o luto emocionadamente antecipado, quando o profissional lamenta o estado do doente referindo-se a ele como se já estivesse morto, até atitudes que à primeira vista poderiam sugerir certa frieza ou alienação. Q uanto aos doentes, há os que preferem estar rodeados por parentes e amigos e os que optam pelo isolamento, pelo recolhimento paulatino da vida. É preciso haver compreensão e respeito pelas diferenças, deles e nossas, sem contudo esquecer que 0 paciente ainda, ou agora, sente dor, mesmo que muitas vezes já não consiga voluntariamente expressá-la. E sente angústia e medo. Assim como aqueles que o rodeiam. E, resguardadas as proporções, como todos nós.

\section{CONSIDERAÇÕES FINAIS}

Para Freud ${ }^{10}$ dor, luto e ansiedade seriam reações à uma perda ou à uma ameaça de perda de um objeto de amor, ou ainda à perda do amor deste objeto. $\mathrm{N}$ asi $0^{23}$ acrescenta que o objeto de amor pode ser a própria pessoa (auto-estima), ou partes do corpo, ou uma outra pessoa, isto não importa, pois a amputação brutal de qualquer desses objetos amados trará uma desarmonia psíquica traduzida por dor, não havendo distinção entre dor física e dor psíquica, posto que "a dor é um fenômeno misto que surge no limite entre corpo e psique".

Finalizando, parece ser importante pesquisar a amplitude de fatores que contribuem para a experiência da dor, e as influências que ela exerce na vida da pessoa e em todos à sua volta. A doença e a dor já não são mais, isoladamente, 0 alvo do tratamento. $D$ eve-se entrelaçar diversos saberes ampliando o foco de atenção e cuidados para além do paciente, a família que dele cuida e a equipe que dele trata.

\section{REFERÊNCIAS BIBLIOGRÁFICAS}

1. Verhaak PFM, Kerssens JJ, D ekker J, Sorbi MJ, Bensing JM . Prevalence of chronic benign pain 
disorder among adults: a review of the literature. Pain 1998;77:231-9.

2. Tudo sobredor. M ed Report 1999;1(6).

3. World $\mathrm{H}$ ealth $\mathrm{O}$ rganization. $\mathrm{C}$ ancer pain, palliative care and the World $\mathrm{H}$ ealth $\mathrm{O}$ rganization: 2000-2002 priorities. G eneva: WH O; 1999.

4. Caton D. "The poem in the pain": the social significance of pain in western civilization. Anesthesiology 1998;81:1044-52.

5. Foucault M . Vigiar epunir. Petrópolis: Vozes; 1983.

6. Damásio AR. 0 erro de D escartes. Rio de Janeiro: Companhia das Letras; 2000.

7. M aturana $\mathrm{H}$. Emociones y lengaje en education y politica. Santiago: Pedagógicas Chilenas; 1990.

8. Freud S. Projeto para umapsicologiacientífica. Rio de Janeiro: Imago; 1976. (O bras Completas; vol.1).

9. Freud S. Além do princípio de prazer. Rio de Janeiro: Imago; 1976. (O bras Completas; vol.18).

10. Freud S. Inibições, sintomas eansiedade. Rio de J aneiro: I mago; 1976. (O bras Completas; vol. 20).

11. Kowács M J, C arvalhoVA. Q ualidade de vida em pacientes com câncer. In: N ascimentoSchulzeC M , organizador. D imensões da dor no câncer. São Paulo: RobeEditorial; 1997.

12. Gamsa A. Therole of psychological factorsin chronic pain: a half century of study. Pain 1994;57:5-15

13. Watzlawick P. Pragmática da comunicação humana. São Paulo: Cultrix; 1972.

14. Rapizo R. Teoria sistêmica de família. Rio de Janeiro: Instituto N oos; 1996.

15. International Association for the Study of Pain (IASP). Classification of chronic pain. D escription of pain syndromes and definition of pain terms. Pain 1986;(Suppl S3).

16. Cailliet R. D or: mecanismo etratamento. Porto Alegre: Artmed; 1999.

17. Biondi M , Picardi A. Psychological stress and neuroendocrine function in humans: the last two decades of research. Psychother Psychosom 1999;68:114-50.

18. Caetano D, C aetano SC, K rämer $\mathrm{M} \mathrm{H}$. Psiconeuroimunoendocrinologia. J Bras Psiquiatr 1999;48(7):307-14.

19. M elzack $R$, Loeser RJ. Phantom body pain in paraplegies: evidence for a central " pattern generating mechanism for pain". Pain 1978; 4:195-210.

20. Portenoy RK. D or neuropática. In: Kanner R. Segredos em clínica de dor. Porto Alegre: Artmed; 1998.

21- Freud S. N ovas conferênciasintrodutórias sobre psicanálise Rio deJ aneiro: Imago; 1976. (O bras Completas; vol. 22).

22. Japiassu H. Introdução ao pensamento epistemológico. Rio deJ aneiro: Francisco Alves; 1977.

23. N asio JD. 0 livro da dor e do amor. Rio de Janeiro: JorgeZahar; 1997.

24. Foucault M . A verdadee asformasjurídicas. In: CadernosdaPU C-RJ. Rio de Janero: PU C; 1979.

25. Cleeland CS. The impact of pain on the patient with cancer. C ancer 1984;54:2635-41.

26. ClarkeW C, Kashani A, Clark SB. A mensuração da dor. In: Kanner R. Segredos em clínica de dor. Porto Alegre: Artmed; 1998.

27. M iaskowski C, Zimmer EF, Barret, KM , D ibble $S L$, Wal hagen M. Differences in patients and family caregivers perceptions of the pain experience influence patient and care giver outcomes. Pain 1997;72:217-26.

28. Averill PM , N ovy D M , N elson D V, Berry LA. Correlates of depression in chronic pain patients: a comprehensive examination. Pain 1996; 65:93-100.

29. LesageP, Portenoy RK. Trendsin cancer pain management. Cancer Control 1999;6(2):136-45.

30. Instituto $\mathrm{N}$ acional de Câncer (Brasil). Estimativas da incidência e mortalidade por câncer no Brasil. Rio de Janeiro: IN CA; 2001.

31. Stjernswärd J. PalliativeM edicine: aglobal perspective. O xford U niversity Press; 1993.

32. Strang P. C ancer pain: a provoker of emotional, social and existencial distress. Acta 0 ncol 1998;37(7/8):641-4.

33. Zaza C, Sellick SM, W illan A, Reyno L, Browman GP. H ealth careprofessionalsfamiliarity with non-pharmacological strategies for managing cancer pain. Psycho-O ncology 1999;8:99-111.

34. World $\mathrm{H}$ ealth $\mathrm{O}$ rganization. $\mathrm{C}$ ancer pain relief: with aguideto opioid availability. G enebra: WH $0 ; 1996$.

35. M cC racken LM . Learning to live with thepain: acceptance of pain predicts adjustment in personswith chronic pain. Pain 1998;74:21-7.

36. KatzWA. Theneeds of a patient in pain. Am J 
M ed 1998;105(1B):25-75.

37. World $\mathrm{H}$ ealth $\mathrm{O}$ rganization. Pain in children with cancer: theW orld $\mathrm{H}$ ealth $\mathrm{O}$ rganization IASP guidelines. Genebra:WH 0; 1999.
38. Schisler EL. 0 conceito da dor total no câncer. In: N ascimento-Schulze CM, organizador. Dimensões da dor no câncer. São Paulo: Robe Editorial; 1997. 